\title{
Renal function as a predicting model for plasma methotrexate concentration after high-dose methotrexate chemotherapy in pediatric malignancy
}

\author{
Kaveh Jaseb $^{1}$, Ehsan Ghaedi ${ }^{2,1}$, Mohadeseh Shahin ${ }^{3}$, Majid Mirmohamadkhani ${ }^{4}$, Parisa Javadian ${ }^{5}$, Sabahat Haghi ${ }^{3^{*}}$ \\ ${ }^{1}$ Thalassemia and Hemoglobinopathies Research Centre, Health Research Institute, Ahvaz Jundishapur University of Medical Sciences, Ahvaz, Iran \\ ${ }^{2}$ Department of Cellular and Molecular Nutrition, School of Nutritional Sciences and Dietetics, Tehran University of Medical Sciences, Tehran, Iran \\ ${ }^{3}$ Department of Pediatrics (Hematology and Oncology), AmiralmomeninMedical, Educational Center, Semnan University of Medical Sciences, \\ Semnan, Iran \\ ${ }^{4}$ Department of Community Medicine, Social Determinants of Health Research Center, Semnan University of Medical Sciences, Semnan, Iran \\ ${ }^{5}$ Department of Internal Medicine, School of Medicine, Shahrekord University of Medical Sciences; Shahrekord, Iran
}

\section{A R T I C L E I N F O}

Article Type:

Original Article

\section{Article History:}

Received: 7 July 2017

Accepted: 13 November 2017

ePublished: 24 November 2017

\section{Keywords:}

Methotrexate concentration

Creatinine

Creatinine clearance

Renal toxicity

\begin{abstract}
A B S T R A C T
Introduction: Methotrexate (MTX) is the most generally administered antimetabolite in pediatric cancers. Renal excretion is the major route of elimination of MTX. However, renal toxicity and delayed MTX elimination is a particular concern and direct serum MTX concentration is a gold standard for renal toxicity monitoring. However, checking plasma MTX concentrations in most oncology institutions is not always possible especially in less developed countries.

Objectives: The purpose of this study was to further assess the renal function after administration of high-dose MTX by parameters such as serum creatinine and Cr clearance rate.

Patients and Methods: This is a cross-sectional descriptive analytic study. The study was conducted on children with acute lymphoblastic leukemia, non-Hodgkin lymphoma and osteosarcoma receiving high doses MTX. Patients' age was ranged from 5 to 16 years. Serum MTX concentration and serum Cr were measured at 24, 48 and 96 hours after receiving MTX and then $\mathrm{Cr}$ clearance calculated based on available formulas. All the statistical analyses were done by SPSS 20.0 statistical software

Results: This study was performed on 4 patients with osteosarcoma, 3 patients with leukemia and one patient with lymphoma. MTX concentration reduced significantly during 96 hours $(P<0.001)$. A significant correlation between $\mathrm{Cr}$ clearance at 48 hours and the average of serum MTX concentration $(P=0.001)$ were observed. Furthermore there were significant correlations between $\mathrm{Cr}$ at 24 hours $(P=0.003), 48$ hours $(P=0.009)$ and 96 hours $(P=0.044)$, with the average of serum MTX concentration.

Conclusion: Our findings indicated that serum $\mathrm{Cr}$ and $\mathrm{Cr}$ clearance can be used to estimate the average of serum MTX concentrations.
\end{abstract}

\section{Implication for health policy/practice/research/medical education:}

Predicting the possible side effects of methotrexate, play an important role during chemotherapy regimens. If predicted dose reduced because of unfavorable side effects, not only chemotherapy regimens may fail but also the risk of relapse increase. Nephrotoxicity is one of important side effect of this drug. Thus possible model for predicting renal function after high-dose methotrexate therapy could prevent adverse outcomes.

Please cite this paper as: Jaseb K, Ghaedi E, Shahin M, Mirmohamadkhani M, Javadian P, Haghi S. Renal function as a predicting model for plasma methotrexate concentration after high-dose methotrexate chemotherapy in pediatric malignancy. J Nephropharmacol. 2017;7(2):74-79.

\section{Introduction}

Methotrexate (MTX) is the most generally administered antimetabolite in pediatric cancers which can causes considerable improvements in the long-term survival of these patients $(1,2)$. Renal excretion is the major route of elimination of MTX. Almost $70 \%-90 \%$ of the dose is excreted unaffected in the urine, most within the first 6 hours (3). High-dose MTX (HDMTX) defined by MTX 
doses $\geq 1 \mathrm{~g} / \mathrm{m}^{2}$ is the important part of most chemotherapy regimens (4). The cytotoxic effects of MTX could be amended by folinic acid (leucovorin) which allows for the administration of higher doses (up to $33.6 \mathrm{~g} / \mathrm{m}^{2}$ ) $(5,6)$. MTX concentrations $>1 \mu \mathrm{mol} / \mathrm{L}$ at 48 hours or $>0.1$ $\mu \mathrm{mol} / \mathrm{L}$ at 72 hours after administration are associated with increased risk of toxicity in spite of increased leucovorin rescue (7). Renal toxicity is a particular concern of delayed MTX elimination after administration of $\operatorname{HDMTX}(8,9)$ along with other side effects including hepatotoxicity, mucositis, bone marrow suppression, secondary infection, and delays in the next course of chemotherapy (8). MTX concentrations lower than optimal levels increase the risk of relapse (10). Inflammation, reactive oxygen species, and neutrophil infiltration are implicated in the pathogenesis of MTX-induced renal damage (11). The possible explanation could be development of HDMTX-induced acute renal dysfunction which is mediated by crystalinduced obstacle due to precipitation of MTX or 7-OH MTX in the nephrons, diminished renal perfusion from afferent arteriolar vasoconstriction (12) or straight toxic effect on tubular cells. It has been reported that HDMTX may lead to renal toxicity in more than $40 \%$ of patients (12). Widemann et al reported that the incidence of MTX nephrotoxicity is $1.8 \%$ in osteosarcoma patients, but the incidence of nephrotoxicity in hematologic malignancies is not well-defined (13).

In spite of pharmacokinetic models of HDMTX to predict severe side effects, because of limitation of these models, serum MTX concentration monitoring is still a gold standard for defining patients at high risk of developing HDMTX renal toxicity (14). However, checking plasma MTX concentrations in most oncology institutions is not always possible specially in less developed countries (15). Hence, it is of great significance to find other means of monitoring plasma MTX concentrations. It has been hypothesized that evaluation of renal function by calculating the creatinine clearance and/or serum $\mathrm{Cr}$ may be appropriate means of monitoring plasma MTX concentrations instead of straight plasma measurement (3). Skärby et al previously reported that the increase in serum creatinine $(\mathrm{Cr})$ concentration within the first 12 to 24 hours after the start of MTX infusion was a suitable predictor of delayed excretion of MTX in children with acute lymphoblastic leukemia (16).

\section{Objectives}

The purpose of this study was to further assess the change of renal function after administration of HDMTX by parameters such as serum $\mathrm{Cr}$ and $\mathrm{Cr}$ clearance at various time points in children receiving HDMTX. Possible association between serum MTX concentrations and $\mathrm{Cr}$ clearance would be investigated to find out helpful parameters for predicting delayed MTX elimination.

Patients and Methods

Patients

This study involved 4 patients with osteosarcoma (7/16 of hospitalized patients), 2 patients with acute lymphoblastic leukemia (4/16 hospitalized patients) and 2 patients with Burkitt lymphoma (5/16 hospitalized patients) who were treated at Amiralmomenin hospital in Semnan and Shafa hospital in Ahvaz from May 2014 to June 2015.

\section{Treatment \\ High dose MTX regimen}

HDMTX was administered after consolidation during maintenance therapy. HDMTX was given only if absolute neutrophil count was $>1.0 \times 10^{9} / \mathrm{L}$, platelet count was $\geq 80 \times 10^{9} / \mathrm{L}$ and white blood cell count $\geq 3.0 \times 10^{9} / \mathrm{L}$ with normal liver and kidney function, and no evidence of pleural effusion on chest radiograph. Inclusion criteria included 1) age $<16$ years and 2) HDMTX dose $\geq 1 \mathrm{~g} / \mathrm{m}^{2}$. Exclusion criteria included a lack of recorded MTX serum levels at 24, 48, and 72 hours after MTX administration. Osteosarcoma patients received $12-20 \mathrm{~g} / \mathrm{m}^{2}$ MTX, patients with Burkit lymphoma received $3 \mathrm{~g} / \mathrm{m}^{2}$ and ALL $5 \mathrm{~g} / \mathrm{m}^{2}$. The initial dose (1/5-1/6 of the full dose; no more than $500 \mathrm{mg}$ ) was intravenously transfused in 1 hour. The remainder was infused during the following 23 hours. In the first phase (hyper-hydration and urine alkalinization) 2-4 L/m² serum normal saline $+40 \mathrm{mEq} / \mathrm{L} 5 \% \mathrm{NaHCO} 3$ were given at 12 hours before MTX infusion until urine $\mathrm{pH}$ reach $>7.5$ for all patients.

\section{Leucovorin rescue}

Leucovorin rescue was started 36 hours after MTX transfusion. The dose was $15 \mathrm{mg} / \mathrm{m}^{2}$ for all patients despite any dose of MTX. Serum MTX concentrations were not considered to estimate the leucovorin rescue.

\section{Sample acquisition and analysis}

Measurement of plasma MTX concentrations

Blood samples were centrifuged at $3000 \mathrm{~g}$ for 5 minutes at room temperature in tubes without any anticoagulant. Plasma MTX concentrations were measured by high performance liquid chromatography (HPLC, Agilent 1100, USA-Mas Germany) with UV detector at $305 \mathrm{~nm}$ and a quantification limit of $0.01 \mu \mathrm{mol} / \mathrm{L}$ at 24,48 , and 96 hours after the start of treatment. A mixture of phosphate buffer and acetonitrile with $\mathrm{pH} 3.5$ formed the mobile phase. Plasma levels of MTX were reported in micromoles per liter $(\mu \mathrm{mol} / \mathrm{L})$. Delayed elimination was defined by either MTX concentrations $\geq 1 \mu \mathrm{mol} / \mathrm{L}$ at 48 hours or $\geq 0.1$ $\mu \mathrm{mol} / \mathrm{L}$ at 72 hours (17).

\section{Measurement of $\mathrm{Cr}$ clearance rate and serum $\mathrm{Cr}$ concentration}

The 24-hour urine samples were attained over the first 96 hours after beginning chemotherapy $(0,24,48$ and 96 hours) and treated with $6 \mathrm{~N} \mathrm{HCl}$ as preservative. Measurement of urine $\mathrm{Cr}$ concentration was based on a fraction of the sample. During the last hour of urine sample attainment, a venous blood sample was drawn for serum $\mathrm{Cr}$ concentrations using the Cockcroft-Gault equation. 


\section{Ethical issues}

The study was approved by the research ethics committee of Semnan University of Medical Sciences (\#93.562629), and in all stages of research, the provisions of the Declaration of Helsinki and the directives of the ethics committee of the ministry of health were observed. All participants signed an informed consent of ethics committee.

\section{Statistical analysis}

Spearman's rank correlation was applied to determine potential effectors. Potential effectors for toxicities were then addressed by logistic regression analysis. If $P$ value was less than 0.05 in any analysis, it was considered statistically significant. All the statistical analysis were done by SPSS 20.0 statistical software (SPSS Inc., Chicago, IL, USA).

\section{Results}

The baseline demographic and clinical characteristics of the patients were summarized in Table 1 . Most children were male $(62.5 \%)$ and had grade I disease $(37.5 \%)$ with a median age of 11.62 years (range: 5 years to 16 years). A

Table 1. Demographic characteristics of patients at baseline

\begin{tabular}{|c|c|}
\hline Characteristic & \\
\hline Age $(y)$, mean $\pm S D$ & $11.62 \pm 4.17$ \\
\hline \multicolumn{2}{|l|}{ Gender (\%) } \\
\hline Boys & $\begin{array}{l}50 \% \text { of hospitalization } \\
62.5 \% \text { of patients }\end{array}$ \\
\hline Girls & $\begin{array}{l}50 \% \text { of hospitalization } \\
37.5 \% \text { of patients }\end{array}$ \\
\hline Weight $(\mathrm{kg})$, mean \pm SD & $32.93 \pm 12.14$ \\
\hline $\operatorname{BSA}\left(m^{2}\right)$ & $\begin{array}{l}1.01 \text { based on hospitalization and } \\
1.07 \text { based on patients }\end{array}$ \\
\hline MTX dose $\left(\mathrm{g} / \mathrm{m}^{2}\right)$ & Different \\
\hline $\begin{array}{l}\text { Alkalization on first day of } \\
\text { chemotherapy }\left(\mathrm{mL} / \mathrm{m}^{2}\right)\end{array}$ & $\begin{array}{l}40 \mathrm{meq} / \mathrm{L} \\
\mathrm{NaHCO} 3\end{array}$ \\
\hline $\begin{array}{l}\text { Hydration on first day of } \\
\text { chemotherapy }\left(\mathrm{mL} / \mathrm{m}^{2}\right)\end{array}$ & $2-4 \mathrm{~L} / \mathrm{m}^{2}$ \\
\hline
\end{tabular}

total of 16 courses of MTX infusion were observed in this study. As for dosages, 5 courses were $3 \mathrm{~g} / \mathrm{m}^{2}$ and 11 courses were $5 \mathrm{~g} / \mathrm{m}^{2}$. Eight episodes of elimination delay (MTX concentration over 1 at 24 hours and over 0.1 at 96 hours) were observed, accounting for $50 \%$ of total courses. The rate of elimination delay showed no difference between 3 $\mathrm{g} / \mathrm{m}^{2}$ group (B) and $5 \mathrm{~g} / \mathrm{m}^{2}$ group (A). Body weight, age, and body surface area (BSA) were not significantly different between group A and B. Serum Cr concentrations at 24, 48 and 96 hours were higher in group B compared with group A. In contrast, the Cr clearance at 24 and 48 hours was higher in group A compared with group B. Serum Cr concentration and Cr clearance at 24, 48 and 96 hours were higher in the normal elimination group compared with the delayed elimination group.

Serum creatinine at 24, 48 and 96 hour were $0.83,0.87$ and $0.80 \mathrm{mg} / \mathrm{dl}$ (Table 2) and Cr clearances were 60.73, 55.88 and $60.27 \mathrm{~mL} / \mathrm{min}$ respectively (Table 3). MTX concentrations were $0.23,0.17$ and $0.06 \mu \mathrm{mol} / \mathrm{L}$ in 24 , 48 and 96 hours. Then correlation analysis between serum $\mathrm{Cr}$ and $\mathrm{Cr}$ clearance with MTX concentration was performed (Table 4). At first Spearman's rank correlation coefficient of independent variables with dependent variable determined. Our findings showed that there is an inverse correlation between $\mathrm{Cr}$ at $24(r=-0.57, P=0.020)$, $48(\mathrm{r}=-0.57, P=0.020)$ and $96(\mathrm{r}=-0.88, P<0.001)$ hours with MTX concentration (Table 3). Correlation between Cr clearance and MTX concentration was checked with a general linear model. This model revealed that MTX changes during the time were significant $(P=0.008)$. Although when MTX concentration adjusted with $\mathrm{Cr}$ clearance, time of measurement had no significant correlation with measured $\mathrm{Cr}$ clearance, the interaction effect of time and Cr clearance at 48 hours is significant. In the same way $\mathrm{Cr}$ and MTX concentration were checked and data showed that interaction effect of time of measurement has the significant correlation with 48 hours $\mathrm{Cr}(P=0.001)$ and 96 hours $\operatorname{Cr}(P=0.018)$. Moreover, after $\mathrm{Cr}$ effect adjustment and time interaction effect, all of

Table 2. Variables based on methotrexate dose and time elimination between groups

\begin{tabular}{|c|c|c|c|c|}
\hline \multirow{3}{*}{$\begin{array}{l}\text { Overall } \\
\mathrm{N}=16\end{array}$} & \multicolumn{2}{|c|}{ MTX dose } & \multicolumn{2}{|c|}{ MTX elimination } \\
\hline & Group A & Group B & Normal & Delayed \\
\hline & $\mathbf{n}=\mathbf{5}$ & $\mathrm{n}=11$ & $\mathrm{n}=\mathbf{8}$ & $\mathrm{n}=\mathbf{8}$ \\
\hline \multirow{2}{*}{ Body weight (kg) } & Patients 23.75 & Patients 36 & Patients 38 & Patients $24.5 r \varepsilon, 0$ \\
\hline & Hospitalization 20 & Hospitalization 33.45 & Hospitalization 38.75 & Hospitalization 19.75 \\
\hline \multirow{2}{*}{ Age (y) } & Patients 8 & Patients 12.83 & Patients 13.6 & Patients 8.3 \\
\hline & Hospitalization 6.8 & Hospitalization 11.72 & Hospitalization 13.75 & Hospitalization 6.625 \\
\hline \multirow{2}{*}{$\operatorname{BSA}\left(\mathrm{m}^{2}\right)$} & Patients 0.9 & Patients 1.13 & Patients 1.12 & Patients 1.09 \\
\hline & Hos 0.9 & Hos 1.07 & Hos 1.125 & Hos 1.22 \\
\hline Serum Cr 24 h (mg/dL) & 0.62 & 0.93 & 1.09 & 0.583 \\
\hline Serum $\mathrm{Cr} 48 \mathrm{~h}(\mathrm{mg} / \mathrm{dL})$ & 0.575 & 1.1 & 1.15 & 0.7 \\
\hline Serum Cr 96 h (mg/dL) & 0.56 & 0.9 & 1.035 & 0.64 \\
\hline Cr clearance (mL/min), $24 \mathrm{~h}$ & 60.75 & 60.72 & 62.305 & 59.158 \\
\hline $\mathrm{Cr}$ clearance $(\mathrm{mL} / \mathrm{min}), 48 \mathrm{~h}$ & 57.75 & 52.63 & 56.69 & 51.64 \\
\hline $\mathrm{Cr}$ clearance $(\mathrm{mL} / \mathrm{min}), 96 \mathrm{~h}$ & 57.88 & 60.20 & 56.158 & 54.96 \\
\hline
\end{tabular}


Table 3. Correlation between urine $\mathrm{Cr}$ and $\mathrm{Cr}$ clearance with methotrexate concentration at different times

\begin{tabular}{|c|c|c|c|c|c|c|}
\hline & MTX at $24 \mathrm{~h}$ & & MTX at $48 \mathrm{~h}$ & & MTX at $96 \mathrm{~h}$ & \\
\hline & Correlation coefficient & $P$ value & Correlation coefficient & $P$ value & Correlation coefficient & $P$ value \\
\hline \multicolumn{7}{|l|}{ At $24 \mathrm{~h}$} \\
\hline Serum $\mathrm{Cr}$ & -0.57 & 0.02 & -0.57 & 0.02 & -0.88 & 0.00 \\
\hline Cr clearance & 0.08 & 0.75 & 0.06 & 0.82 & 0.01 & 0.97 \\
\hline \multicolumn{7}{|l|}{ At $48 \mathrm{~h}$} \\
\hline Urine $\mathrm{Cr}$ & -0.05 & 0.83 & 0.07 & 0.79 & -0.55 & 0.02 \\
\hline Cr clearance & -0.29 & 0.26 & -0.44 & 0.08 & -0.08 & 0.75 \\
\hline \multicolumn{7}{|l|}{ At $96 \mathrm{~h}$} \\
\hline Serum $\mathrm{Cr}$ & -0.31 & 0.22 & -0.20 & 0.44 & -0.64 & 0.00 \\
\hline Cr clearance & -0.14 & 0.59 & -0.34 & 0.18 & -0.19 & 0.46 \\
\hline
\end{tabular}

Table 4. Variables data in detail

\begin{tabular}{lccc}
\hline & Min & Max & Mean \pm SD \\
\hline At 24 hours & & & \\
MTX concentration $(\mu \mathrm{mol} / \mathrm{L})$ & & & $0.23(0.08)$ \\
Serum Cr $(\mathrm{mg} / \mathrm{dL})$ & 0.50 & 1.60 & $0.83(0.32)$ \\
Cr clearance $(\mathrm{mL} / \mathrm{min})$ & 27.66 & 112.50 & $60.73(22.57)$ \\
At 48 hour & & & \\
MTX concentration $(\mu \mathrm{mol} / \mathrm{L})$ & & & $0.17(0.11)$ \\
Serum Cr $(\mathrm{mg} / \mathrm{dL})$ & 0.29 & 1.60 & $0.87(0.37)$ \\
Cr clearance $(\mathrm{mL} / \mathrm{min})$ & 36.42 & 84.14 & $55.88(15.17)$ \\
At 96 hour & & & \\
MTX concentration $(\mu \mathrm{mol} / \mathrm{L})$ & & & $0.06(0.04)$ \\
Serum Cr $(\mathrm{mg} / \mathrm{dL})$ & 0.40 & 1.30 & $0.80(0.27)$ \\
Cr Clearance $(\mathrm{mL} / \mathrm{min})$ & 40.24 & 86.11 & $60.27(13.93)$ \\
\hline
\end{tabular}

Cr indexes at 24 hours $(P=0.003), 48$ hours $(P=0.009)$ and 96 hours $(P=0.044)$ had the significant correlation with MTX concentration in consequent measurements (Table 5).

\section{Discussion}

It has been reported that HDMTX-regimens have nephrotoxicity incidence of about $1.8 \%$ and a mortality rate of approximately $0.1 \%$, regardless of scheduled drug monitoring and supportive therapy (13). Furthermore, HDMTX-induced nephrotoxicity deteriorates overall drug toxicity by delaying MTX elimination. Strict monitoring of urine output, plasma drug levels, and serum Cr levels besides urine alkalization and hydration to minimize renal toxicity are standard accessories in
HDMTX regimens (7). Other studies have reported that a serum MTX concentration of $1000 \mu \mathrm{mol} / \mathrm{L}$ after a 4 hours infusion and $700 \mu \mathrm{mol} / \mathrm{L}$ after a 6 hours infusion can attain high-quality effectiveness in the treatment of osteosarcoma. However, the administration of higher doses of MTX leads to more severe side effects. The safe range for the area under the curve has been revealed to be between $4000 \mathrm{mM} / \mathrm{h}$ and $12000 \mathrm{mM} / \mathrm{h}$ (18). Although, a number of population-based pharmacokinetic models of HDMTX infusion have been developed, (19-21) because of the considerable difference between patients, the clinical application of these models mainly for patients with delayed elimination of MTX is limited. Thus, we investigated the hypothesis that evaluating renal function may be an appropriate means of monitoring plasma MTX concentrations after HDMTX for pediatric cancers.

Notably the Cr clearance at 48 hours after of HDMTX was significantly correlated with plasma MTX concentrations at 24, 48 and 96 hours. Likewise, 24-hour urine Cr was significantly correlated with plasma MTX concentrations at 24 hours $(P=0.003), 48$ hours $(P=0.009)$ and 96 hours $(P=0.044)$. Of note, the trend of MTX concentration at 24, 48 and 96 hours was decreasing which was accurate and predictable.

Several studies have found the correlation between plasma MTX concentrations and Cr clearance. Hempel et al reported a negative relationship between plasma MTX concentrations and the Cr clearance in mainly childhood patients with ALL, non-Hodgkin lymphoma, osteosarcoma, and brain tumor who received HDMTX (22). $\mathrm{Xu}$ et al (23) reported a significant positive

Table 5. Variance analysis to show correlation between Urine $\mathrm{Cr}$ and $\mathrm{Cr}$ clearance with methotrexate concentration

\begin{tabular}{|c|c|c|c|c|c|}
\hline & Sum of squares & $d f$ & Mean squared & F statistics & $P$ value \\
\hline \multicolumn{6}{|l|}{ At 24 hours } \\
\hline Serum $\mathrm{Cr}$ & 0.023 & 0.023 & 0.023 & 13.744 & 0.003 \\
\hline Cr clearance & 0.013 & 1 & 0.013 & 3.606 & 0.082 \\
\hline \multicolumn{6}{|l|}{ At 48 hours } \\
\hline Serum $\mathrm{Cr}$ & 0.016 & 1 & 0.016 & 9.793 & 0.009 \\
\hline Cr clearance & 0.012 & 1 & 0.012 & 3.125 & 0.102 \\
\hline \multicolumn{6}{|l|}{ At 96 hours } \\
\hline Serum $\mathrm{Cr}$ & 0.008 & 1 & 0.008 & 5.079 & 0.044 \\
\hline Cr clearance & 0.000 & 1 & 0.000 & 0.069 & 0.797 \\
\hline
\end{tabular}


relationship between serum $\mathrm{Cr}$ concentrations at 24 hours and 48 hours with plasma MTX concentrations at 24 (both of them $P<0.001$ ) and 48 hours (both of them $P<0.001$ ). Additionally, previous studies reported the same findings regarding the correlation between $\mathrm{Cr}$ clearance and MTX concentration at the same time $(7,23,24)$. On the contrary, other studies such as Joannon et al (25), Evans et al (26) and Relling et al (27) found that plasma MTX concentration was not correlated with $\mathrm{Cr}$ clearance. Likewise, Kerr et al (28) showed no correlation between MTX clearance and Cr clearance in 18 patients. The lack of agreement with our finding could be clarified by the truth that MTX regimens with lower doses, $1 \mathrm{~g}, 0.9-3.7 \mathrm{~g}$, and 1-2 $\mathrm{g} / \mathrm{m}^{2}$ were administered in these studies respectively which were lower than the dosage in our study. The MTX concentrations in 24 and 48 hours were much lower as well, which means that patients in these studies might undergo a lesser degree of renal function impairment. Also, the kidney has a potent compensatory capacity (29), thus minor injury has least effect on its clearance of MTX. Hence, the dose-responses effect of $\mathrm{Cr}$ clearance variation on MTX elimination may not be clear to a defined degree in these patients.

Results revealed that usual evaluation of renal function could be appropriate for monitoring plasma MTX concentrations when using MTX in high doses over than $3 \mathrm{~g} / \mathrm{m}^{2}$. Thus, straight monitoring of plasma MTX concentrations is not possible.

Although main side effects of MTX such as mucositis, leucopenia and thrombocytopenia observed in patients in our study, we could not draw conclusions concerning association between serum MTX concentration and clinical outcome due to small sample size.

Regression analysis by six variables and deleting low effective parameters was performed. We used backward model for doing the analysis. At first MTX concentration average was measured and then we defined it as a dependent variable. At last, final downgraded regression model as a predictive mean MTX concentration after chemotherapy (Y) was obtained;

$\mathrm{Y}=0.374+0.234(\mathrm{Cr} 48 \mathrm{~h})-0.445(\mathrm{Cr} 96 \mathrm{~h})+0.002(\mathrm{CrCl}$ 24h) $-0.003(\mathrm{CrCl} 96 \mathrm{~h})$

The $r$ square in the final model was 0.85 which represent smaller differences between the observed data and the fitted values. On the other hand, through measurement of 24, 48 and 96 hours $\mathrm{Cr}$ and $\mathrm{Cr}$ clearance 24 and 96 hours after chemotherapy, we can estimate the MTX concentration without expensive analysis just by a simple available method.

\section{Conclusion}

In summary this study demonstrated the relationship between renal function, $\mathrm{Cr}$ clearance and serum $\mathrm{Cr}$ and MTX concentration after HDMTX. According to the $\mathrm{Cr}$ change and $\mathrm{Cr}$ clearance level, physicians could monitor the MTX concentration and adjust alkalization and hydration as early as feasible. Hence, the toxicity of MTX could be reduced. In some institutions where
MTX concentration detection cannot be performed, Cr and $\mathrm{Cr}$ clearance investigation can be a practical means to find out MTX concentration. For patients with high $\mathrm{Cr}$ level/ratio or low $\mathrm{Cr}$ clearance level, they are likely to undergo delayed MTX elimination. Thus, the modalities to improve renal function and increase MTX clearance should be applied accordingly. This study is just initial exploratory study and this model just has the goodness of fit in data. Therefore, validation studies for this model are recommended.

\section{Limitation of the study}

There are some limitations in our study that must be acknowledged. First, heterogeneity in the severity of disease might have influenced results like MTX infusion history before our study. Second, the short follow-up was not adequate to evaluate the extramedullary infiltration rate. Also 7-hydroxy MTX measurement in plasma and urine could help to define the pharmacokinetics of MTX as well as correlation with serum Cr. Direct measurement of glomerular filtration rate facilitates evaluating changes in renal functions more precisely. Also small sample size is another limitation.

\section{Acknowledgments}

The authors gratefully acknowledge the Research Council of Semnan University of Medical Sciences and Health Services for the financial support.

\section{Conflicts of interest}

All the authors declared that they have no conflicts of interest.

\section{Authors' contribution}

KJ, MS, EG and SH performed the research and contributed to design of the study. EG prepared the primary draft. MM contributed to data analysis. PJ and $\mathrm{SH}$ edited the final draft.

\section{Ethical considerations}

Ethical issues (including plagiarism, misconduct, data fabrication, falsification, double publication or submission, redundancy) have been completely observed by the authors.

\section{Funding/Support}

Vice-chancellor of Semnan University of Medical Sciences and Health Services supported this work financially (\#93.562629).

\section{References}

1. Mantadakis E, Cole PD, Kamen BA. High-dose methotrexate in acute lymphoblastic leukemia: where is the evidence for its continued use? Pharmacother. 2005;25:748-55.

2. Liu Y, Xu Y, Lin N, Jiang S, Wang Y, Ye Z. High-dose methotrexate (HD-MTX) used as an adjunct with other chemotherapeutics for the treatment of osteosarcoma. Cell Biochem Biophys. 2015;71:1097-104. doi: 10.1007/s12013014-0314-9. 
3. Pizzo PA, Poplack DG. Principles and Practice of Pediatric Oncology. Lippincott Williams \& Wilkins; 2015.

4. Joerger M, Huitema A, Illerhaus G, Ferreri A. Rational administration schedule for high-dose methotrexate in patients with primary central nervous system lymphoma. Leuk Lymphoma. 2012;53:1867-75. doi: 10.3109/10428194.2012.676177

5. Abramson JS, Hellmann M, Barnes JA, Hammerman P, Toomey C, Takvorian $\mathrm{T}$, et al. Intravenous methotrexate as central nervous system (CNS) prophylaxis is associated with a low risk of CNS recurrence in high-risk patients with diffuse large B-cell lymphoma. Cancer. 2010;116:4283-90. doi: $10.1002 / \mathrm{cncr} .25278$.

6. Cohen IJ. Defining the appropriate dosage of folinic acid after high-dose methotrexate for childhood acute lymphatic leukemia that will prevent neurotoxicity without rescuing malignant cells in the central nervous system. J Pediatr Hematol Oncol. 2004;26:156-63.

7. Tiwari P, Thomas M, Pathania S, Dhawan D, Gupta Y, Vishnubhatla $S$, et al. Serum creatinine versus plasma methotrexate levels to predict toxicities in children receiving high-dose methotrexate. Pediatr Hematol Oncol 2015;32:576-84. doi: 10.3109/08880018.2015.1087612.

8. Xu W, Tang Y, Song H, Shi S, Yang S. Retrospective study on elimination delay of methotrexate in high-dose therapy of childhood acute lymphoblastic leukemia in China. J Pediatr Hematol Oncol. 2007;29:688-93. doi: 10.1097/ MPH.0b013e31814d6777.

9. Takami M, Kuniyoshi Y, Oomukai T, Ishida T, Yamano Y. Severe complications after high-dose methotrexate treatment. Acta Oncologica. 1995;34:611-2.

10. Seidel H, Nygaard R, Moe PJ, Jacobsen G, Lindqvist B, Slørdal L. On the prognostic value of systemic methotrexate clearance in childhood acute lymphocytic leukemia. Leuk Res. 1997;21:429-34.

11. Abraham P, Kolli VK, Rabi S. Melatonin attenuates methotrexate-induced oxidative stress and renal damage in rats. Cell Biochem Funct. 2010;28:426-33. doi: 10.1002/ cbf. 1676 .

12. Widemann BC, Adamson PC. Understanding and managing methotrexate nephrotoxicity. Oncologist. 2006;11:694-703. doi: 10.1634/theoncologist.11-6-694

13. Widemann BC, Balis FM, Kempf-Bielack B, Bielack S, Pratt CB, Ferrari S, et al. High-dose methotrexate-induced nephrotoxicity in patients with osteosarcoma. Cancer. 2004;100:2222-32. doi: 10.1002/cncr.20255.

14. Yang S-L, Zhao F-Y, Song H, Shen D-Y, Xu X-J. Methotrexate associated renal impairment is related to delayed elimination of high-dose methotrexate. Sci World J. 2015;2015:751703. doi: 10.1155/2015/751703.

15. Kapoor G, Sinha R, Abedin S. Experience with high dose methotrexate therapy in childhood acute lymphoblastic leukemia in a tertiary care cancer centre of a developing country. Pediatr Blood Cancer. 2012;59:448-53. doi: 10.1002/ pbc. 24081 .

16. Skärby T, Jönsson P, Hjorth L, Behrentz M, Björk O, Forestier E, et al. High-dose methotrexate: on the relationship of methotrexate elimination time vs renal function and serum methotrexate levels in 1164 courses in 264 Swedish children with acute lymphoblastic leukaemia (ALL). Cancer
Chemother Pharmacol. 2003;51:311-20. doi.org/10.1007/ s00280-002-0552-1

17. Evans WE, Jusko WJ, Schentag JJ. Applied Pharmacokinetics. Spokane: Applied Therapeutics:1981.

18. Comandone A, Passera R, Boglione A, Tagini V, Ferrari $S$, Cattel L. High dose methotrexate in adult patients with osteosarcoma: clinical and pharmacokinetic results. Acta Oncologica. 2005;44:406-11. doi: 10.1080/02841860510029770

19. Piard C, Bressolle F, Fakhoury M, Zhang D, Yacouben K, Rieutord A, et al. A limited sampling strategy to estimate individual pharmacokinetic parameters of methotrexate in children with acute lymphoblastic leukemia. Cancer Chemother Pharmacol. 2007;60:609-20. doi: 10.1007/ s00280-006-0394-3

20. Min Y, Qiang F, Peng L, Zhu Z. High dose methotrexate population pharmacokinetics and Bayesian estimation in patients with lymphoid malignancy. Biopharm Drug Dispos. 2009:30:437-47. doi: 10.1002/bdd.678.

21. Aumente D, Buelga DS, Lukas JC, Gomez P, Torres A, García MJ. Population pharmacokinetics of high-dose methotrexate in children with acute lymphoblastic leukaemia. Clin Pharmacokinet. 2006;45:1227-38.

22. Hempel L, Misselwitz J, Fleck C, Kentouche K, Leder C, Appenroth $\mathrm{D}$, et al. Influence of high-dose methotrexate therapy (HD-MTX) on glomerular and tubular kidney function. Pediatr Blood Cancer 2003;40:348-54. doi: 10.1002/ mpo.10293

23. Xu W-q, Zhang L-y, Chen X-y, Pan B-h, Mao J-q, Song H, et al. Serum creatinine and creatinine clearance for predicting plasma methotrexate concentrations after high-dose methotrexate chemotherapy for the treatment for childhood lymphoblastic malignancies. Cancer Chemother Pharmacol. 2014; 73:79-86. doi: 10.1007/s00280-013-2319-2.

24. Mao J, Zhang L, Shen H, Tang Y, Song H, Zhao F, et al Creatinine clearance rate and serum creatinine concentration are related to delayed methotrexate elimination in children with lymphoblastic malignancies. Neoplasma. 2014;61:7782.

25. Joannon P, Oviedo I, Campbell M, Tordecilla J. High-dose methotrexate therapy of childhood acute lymphoblastic leukemia: Lack of relation between serum methotrexate concentration and creatinine clearance. Pediatr Blood Cancer. 2004;43:17-22. doi: 10.1002/pbc.20032

26. Evans W, Stewart C, Chen C-H, Crom W, Bowman WP, Abromowitch $\mathrm{M}$, et al. Methotrexate systemic clearance influences probability of relapse in children with standardrisk acute lymphocytic leukaemia. Lancet. 1984;323:359-62.

27. Relling MV, Fairclough D, Ayers D, Crom WR, Rodman JH, Pui C-H, et al. Patient characteristics associated with highrisk methotrexate concentrations and toxicity. J Clin Oncol. 1994;12:1667-72. doi: 10.1200/JCO.1994.12.8.1667.

28. Kerr IG, Jolivet J, Collins JM, Drake JC, Chabner BA. Test dose for predicting high-dose methotrexate infusions. Clin Pharmacol Ther. 1983;33:44-51.

29. Borsi JD, Revesz T, Schuler D. Prognostic importance of systemic clearance of methotrexate in childhood acute lymphoblastic leukemia. Cancer Chemother Pharmacol. 1987;19:261-4. doi: 10.1007/BF00252984.

Copyright $\odot 2018$ The Author(s); Published by Society of Diabetic Nephropathy Prevention. This is an open-access article distributed under the terms of the Creative Commons Attribution License (http://creativecommons.org/licenses/by/4.0), which permits unrestricted use, distribution, and reproduction in any medium, provided the original work is properly cited. 